\title{
Ocular Manifestations of Post-Acute COVID-19 Syndrome, Upper Egypt Early Report
}

\author{
Dalia Tohamy $\mathbb{1}^{\prime}$ \\ Mohamed Sharaf' \\ Khaled Abdelazeem (D) \\ Mohamed GA Saleh' \\ Mahmoud F Rateb \\ Wael Soliman' \\ Salma M Kedwany (D) ${ }^{\prime}$ \\ Mohamed Omar Abdelmalek ${ }^{2}$ \\ Mohammed A Medhat $\mathbb{D}^{2}$ \\ Amal M Tohamy ${ }^{3}$ \\ Hany Mahmoud (iD ${ }^{4}$ \\ 'Ophthalmology Department, Assiut \\ University, Assiut, Egypt; ${ }^{2}$ Tropical \\ Medicine and Gastroenterology \\ Department, Assiut University, Assiut, \\ Egypt; ${ }^{3}$ Neuology Department, Assiut \\ University, Assiut, Egypt; ${ }^{4}$ Ophthalmology \\ Department, Sohag University, Sohag, \\ Egypt
}

Correspondence: Hany Mahmoud Ophthalmology Department, Sohag University, Almohafza Street, Sohag, 825 II, Egypt

Tel +20 l024368III

Email drhanymahmoud@gmail.com
Purpose: To evaluate the ocular manifestations of post-acute COVID-19 syndrome.

Methods: A retrospective, comparative study included 100 patients who had recovered from COVID-19 and 100 controls who were recruited by stratified randomization from hospital registration system and analyzed regarding history, full ophthalmological examination, general examination including internal medicine and neurological evaluation. Laboratory tests were done.

Results: Mean \pm SD of age were $55.5 \pm 6.2$ in COVID group vs $56.5 \pm 5.8$ in control group; $\mathrm{P}$ value $=0.7$. In COVID group, 57 patients $(57 \%)$ were males vs 51 patients $(51 \%)$ in control group $(\mathrm{P}$ value $=0.39)$, the other compared parameters including history and risk factors showed non-significant difference except for ESR and D-dimer which were elevated in COVID group. In COVID group, 5 patients (5\%) were having retinal vascular occlusion, 2 patients $(2 \%)$ were having anterior ischemic optic neuropathy AION, 3 patients $(3 \%)$ were having uveitis and 2 patients $(2 \%)$ were having central serous chorioretinopathy CSCR. While in control group, 2 patients $(2 \%)$ were having retinal vascular occlusion, and none had AION, uveitis or CSCR (P value $=0.006)$.

Conclusion: Post-acute COVID-19 syndrome could affect the eyes in the form of coagulation problems, neurological morbidities, and other manifestations. This necessitates meticulous follow-up of recovered patients from COVID-19.

Keywords: eye, post-acute COVID-19, Upper Egypt, coagulation, follow-up

\section{Introduction}

Since the emergence of the coronavirus in Wuhan china in 2019 many studies have predicted its ocular manifestations including follicular conjunctivitis, subconjunctival hemorrhage, redness, and eye dryness. Exposure keratitis and mucopurulent conjunctivitis (MPC) were found especially in patients admitted to intensive care units which could be due to the exposure of open mask oxygen or eye exposure. Ocular manifestations could be the first symptoms to appear in some infected patients. ${ }^{1-3}$ A new term emerged as a result of lockdown (Quarantine Dry Eye) which was attributed to personal behavior in both developed and developing countries, this necessitates the change in the treatment and follow-up modalities of those patients. ${ }^{4}$

The appearance of ocular manifestations, drive the ophthalmologists to give medications in the form of eye drops, Some of them have antiviral activities and their use could raise confusion to the physicians as they could affect the level of the virus in the conjunctival tears and secretions. ${ }^{5}$

The presence of the virus in the conjunctival tears and secretions revealed the possibility of its transmission through ocular secretions and could explain the deaths 
amongst ophthalmologists. Also many researches estimated the immune response to the virus in the eye by estimating immunoglobulin (A IgA). ${ }^{6-13}$ Even with no conjunctival manifestations, the virus could be found in the tears enforcing the need of safety measures during ophthalmology practice which could by using protective goggles, social distances in clinics, and even full personal protective equipment (PPE). Some studies evaluated the safe ophthalmology practice amongst ophthalmologists which was different according to safety protocols in the hospitals or the country protocols. ${ }^{14-16}$

It was a surprise to talk about post-acute COVID-19 syndrome or long COVID syndrome, which was defined by National Institute of Health (NIH), Center of Disease Control (CDC), and the World Health Organization (WHO). It means the presence or appearance of long term effects of coronavirus on different body systems. ${ }^{17}$ It is described as causing general fatigue, respiratory, cardiac, or psychological manifestations. The eye could also be affected in post-acute COVID-19 syndrome and some reports have suggested this, but multicenter or worldwide studies are still deficient. ${ }^{18-22}$

In this study we aim to evaluate the ocular manifestations of post-acute COVID-19 or long COVID syndrome in Upper Egypt.

\section{Patients and Methods}

\section{Ethical Considerations}

Full ethical considerations were followed according to Sohag University Ethical Committee: IBR registration number: Soh-Med-21-05-24, they are adherent to the Helsinki Declaration. Written informed consent was taken from all participants.

All investigations were done freely to the patients.

\section{Study Design}

Retrospective comparative study

COVID group: 100 post-acute COVID-19 patients were recruited randomly by stratified randomization from hospital registrations; they were admitted between September 2020 and March 2021 the recovery is defined by two consecutive negative nasopharyngeal swabs with disappearance of the symptoms.

Control group: 100 controls were recruited randomly by stratified randomization from hospital registration system; they were not admitted or diagnosed as COVID-19 patients previously. They were confirmed by nasopharyngeal swab after recruitment and the measurement of immunoglobulin (G IgG) levels.

Data were collected from ophthalmological department registration system of both groups showed non-significant difference in past ocular diseases of significant importance related to this study $\mathrm{P}$ value $>0.05$.

Both groups were screened ophthalmologically; slit lamp biomicroscopy (Version 1.5.0.0, Nidek Co, Ltd), the visual acuity was measured using Snellen chart, intraocular pressure IOP using Goldmann applanation tonometer Goldmann AT 900 (Haag Streit, Bern, Switzerland), fundus examination, and investigations like fluorescein angiography F/A Deep Range Imaging (DRI) Triton SS-OCT (Topcon Corporation, Tokyo, Japan) and optical coherence tomography OCT Deep Range Imaging (DRI) Triton SSOCT (Topcon Corporation, Tokyo, Japan) were done for patients with positive findings.

COVID-19 manifestations were categorized as mild, moderate, and severe according to guidelines. Patients who underwent assisted ventilation were also registered and stratified. Full general examination was done regarding vascular and endocrine systems, neurological evaluation, and evaluation for autoimmune diseases or coagulation disorders. Laboratory investigations were done for patients with positive findings including: D-dimer, erythrocytes sedimentation rate (ESR), and immunological tests.

\section{Inclusion Criteria COVID Group}

100 post-acute COVID-19 patients were recruited randomly from hospital registrations; they were admitted between September 2020 and March 2021 the recovery is defined by two consecutive negative nasopharyngeal swabs with disappearance of the symptoms.

\section{Control Group}

One-hundred controls were recruited randomly from hospital registration system; they were not admitted or diagnosed as COVID-19 patients previously. They were confirmed by nasopharyngeal swab after recruitment and the measurement of immunoglobulin G IgG levels. They did not receive any type of vaccination.

Both groups were matched regarding: age, sex, general condition, chronic diseases, and past ocular diseases.

\section{Exclusion Criteria}

Patients under 18 years of age were excluded. 
Recovered patients from COVID-19 more than 3 months.

The data was collected and analyzed.

\section{Statistical Analysis}

Statistical analysis was conducted using SPSS software (IBM SPSS Statistics for Windows, version 19.0 (IBM Corp., Armonk, N.Y., USA). The age and D-dimer variables were considered as continuous quantitative variables. The remaining variables were considered as qualitative variables. Assimilability to normal distribution was evaluated using the Shapiro-Wilk test. Univariate comparison between the two groups was performed using the Mann-Whitney $U$-test for quantitative variables and Chi-square $\chi^{2}$ test for qualitative variables. Correlation was done by the Spearman test, the strength of correlation was defined as negligible $(r<$ $0.20)$, weak $(0.21<r<0.40)$, moderate $(0.41<r<0.70)$ or strong $(0.71<r<1)$.

\section{Results}

Using the Shapiro-Wilk test, the sample was normally distributed $(\mathrm{P}>0.05)$. The sample size was calculated with 95\% confidential interval, significant Alpha level, Mean + SD of age were (55.5 \pm 6.2 in COVID group vs $56.5 \pm 5.8$ in control group; $\mathrm{P}=0.70$ ). In COVID group, 57 patients $(57 \%)$ where males vs 51 patients $(51 \%)$ in control group $(\mathrm{P}$ value $=0.39) .23$ patients $(23 \%)$ in COVID group had history of diabetes mellitus vs 17 $(17 \%)$ patients in control group $(\mathrm{P}$ value $=0.29)$. Systemic hypertension was present in 15 patients $(15 \%)$ in COVID group vs 23 patients $(23 \%)$ in control group ( $\mathrm{P}$ value $=0.15) .8$ patients $(8 \%)$ in COVID group had history of heart disease vs 7 (7\%) patients in control group $(\mathrm{P}$ value $=0.79)$. Autoimmune disease was present in 6 patients $(6 \%)$ in COVID group vs 5 patients $(5 \%)$ in control group $(\mathrm{P}$ value $=0.76) .67$ patients (67\%) in COVID group had history of previous ocular operation vs $70(70 \%)$ patients in control group $(\mathrm{P}$ value $=0.65)$. In each of the two groups 6 patients (6\%) had previous history of ocular vascular occlusion $(\mathrm{P}$ value $=0.76)$; and $8(8 \%)$ patients in COVID group and $7(7 \%)$ patients in control group had previous history of neurological disorders $(\mathrm{P}$ value $=0.79)$. There is non-significant family history in both groups. The COVID group had a history of previous admission to hospital because they were COVID +ve patients. Mean + SD duration of admission was $25.5 \pm 7.2$ days with 12 patients $(12 \%)$ needed assisted ventilation. D-dimer was (884.28 \pm 1031.42 COVID group vs $465.44 \pm 692.78$ control group; $\mathrm{P}<0.001$ ) (Figure 1). ESR was elevated in 28 patients (28\%) in COVID group vs 11 patients (11\%) in control group $(\mathrm{P}$ value $=0.002)$ (Figure 2$)$. This is shown in Tables 1 and 2, the change of ESR and D-dimer values are shown in Table 3 showing stratification of patients who developed ocular signs, elevated ESR and D-Dimer at follow-up period with decreased values over the time.

In COVID group the patients were classified to mild $(30 \%)$, moderate $(25 \%)$, and severe $(45 \%)$ according to general manifestations and known guidelines (Table 4). The correlation between the severity of COVID-19 clinical manifestations and ocular signs was statistically weak. Moreover, correlation

\section{D dimer}

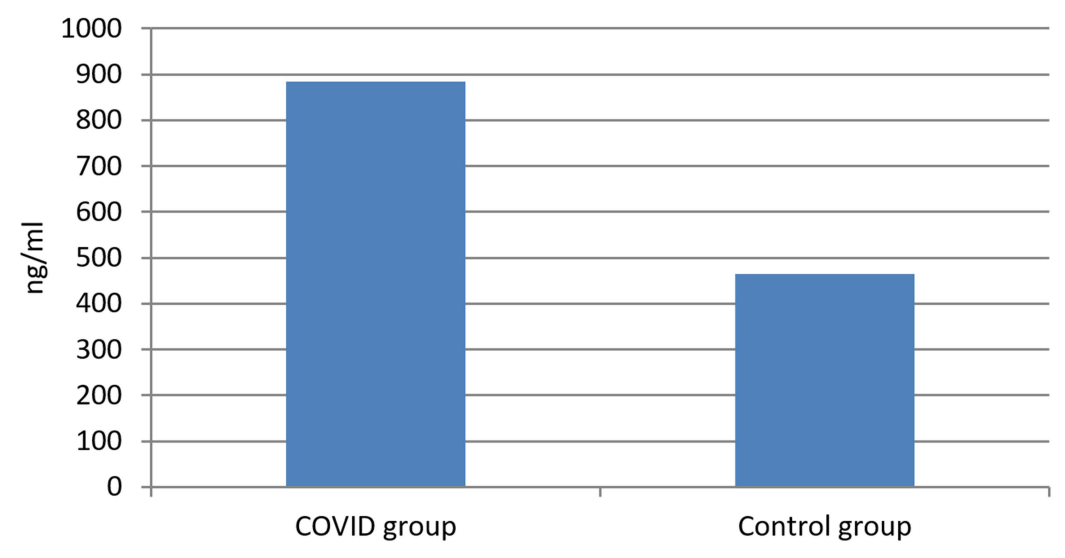

Figure I Significant difference in D-dimer values between both groups. 
ESR

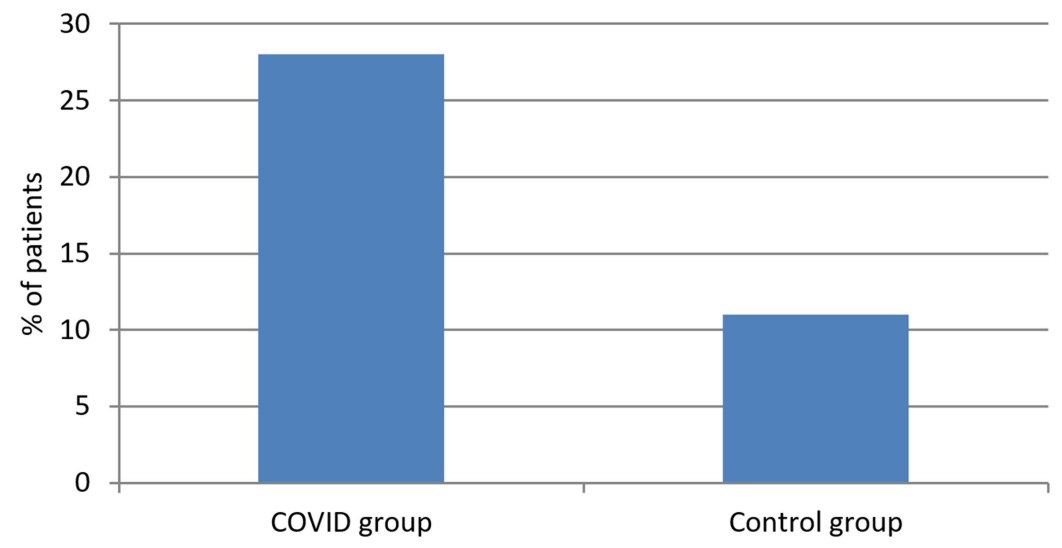

Figure 2 Significant difference in ESR values between both groups.

between assisted ventilation and ocular signs was also weak.

In COVID group, 5 patients (5\%) were having retinal vascular occlusion either branch retinal vein occlusion (BRVO) or central retinal artery occlusion (CRAO), 2 patients $(2 \%)$ were having anterior ischemic optic neuropathy (AION), 3 patients (3\%) were having uveitis and 2 patients $(2 \%)$ were having central serous chorioretinopathy (CSCR). While in control group, 2 patients (2\%) were having retinal vascular occlusion and none had AION, uveitis or CSCR ( $\mathrm{P}$ value $=0.006$ ). This is shown in Table 5 and Figures 3-7.

The duration between recovery and occurrence of ocular manifestations in COVID group range from one to

Table I Showing the Collected Data

\begin{tabular}{|l|l|}
\hline COVID Group & Control Group \\
\hline Age & Age \\
Sex & Sex \\
Systemic history & Systemic history \\
-Diabetes mellitus & -Diabetes mellitus \\
-Hypertension & -Hypertension \\
-Heart disease & -Heart disease \\
-Autoimmune disease & -Autoimmune disease \\
Past ocular history & Past ocular history \\
-Operations & -Operations \\
-Vascular occlusion & -Vascular occlusion \\
-Neurological disorders & -Neurological disorders \\
Family history & Family history \\
COVID-19 history & IgG levels* \\
-Duration of admission & Nasopharyngeal swab \\
-Assisted ventilation & \\
\hline
\end{tabular}

Note: *Immunoglobulin G levels. three months, the stratification according to duration between recovery and occurrence of ocular manifestation is tabulated in Table 3 with more occurrence in the first month after recovery and least in the third month. Patients were diagnosed and treated according to the guidelines of each case; those with vascular occlusion were investigated by internal medicine specialist to exclude other risk factors for the morbidity. Patients with neurological disorders

Table 2 The Values of Collected Data from Both Groups

\begin{tabular}{|c|c|c|c|}
\hline variable & COVID Group & Control Group & $P$ value \\
\hline Age & $55.5 \pm 6.2$ years & $56.5 \pm 5.8$ years & 0.70 \\
\hline Sex & $57 / 43(M * / F * *)$ & $5 \mathrm{l} / 49$ (M/F) & 0.39 \\
\hline $\begin{array}{l}\text { Systemic history } \\
\text {-Diabetes mellitus } \\
\text {-Hypertension } \\
\text {-Heart disease } \\
\text {-Autoimmune disease }\end{array}$ & $\begin{array}{l}23 \% \\
15 \% \\
8 \% \\
6 \%\end{array}$ & $\begin{array}{l}17 \% \\
23 \% \\
7 \% \\
5 \%\end{array}$ & $\begin{array}{l}0.29 \\
0.15 \\
0.79 \\
0.76\end{array}$ \\
\hline $\begin{array}{l}\text { Past ocular history } \\
\text {-Vascular occlusion } \\
\text {-Neurological disorders }\end{array}$ & & $\begin{array}{l}5 \% \\
7 \%\end{array}$ & $\begin{array}{l}0.76 \\
0.79\end{array}$ \\
\hline Family history & Not significant & Not significant & \\
\hline $\begin{array}{l}\text { COVID-19 history } \\
\text {-Duration of admission } \\
\text {-Assisted ventilation }\end{array}$ & $\begin{array}{l}25.5 \pm 7.2 \text { days } \\
12 \%\end{array}$ & & \\
\hline $\begin{array}{l}\text { Laboratory } \\
\text { D-dimer } \\
\text { Elevated ESR*** }\end{array}$ & $\begin{array}{l}884.28 \pm 1031.42 \\
\mathrm{ng} / \mathrm{mL} \text { ****** } \\
28 \%\end{array}$ & $\begin{array}{l}465.44 \pm 692.78 \\
\mathrm{ng} / \mathrm{mL} * * * * \\
11 \%\end{array}$ & $\begin{array}{l}<0.001 \\
<0.002\end{array}$ \\
\hline
\end{tabular}

Notes: *male; **female; ***Erythrocytes sedimentation rate; ****Nano gram/ milliliter. 
Table 3 Showing Stratification of Patients Developed Ocular Signs, Elevated ESR and D-Dimer at Follow-Up Period

\begin{tabular}{|l|l|l|l|}
\hline & Ocular Signs (\%) & ESR (\%)* & DDimer (Mean士SD) \\
\hline I month & 5 & 62 & $\mid 203.23 \pm 1530.46$ \\
2 month & 4 & 39 & $986.43 \pm \mid 1106.91$ \\
3 month & 3 & 28 & $884.28 \pm 1031.42$ \\
\hline
\end{tabular}

Note: *Erythrocytes sedimentation rate.

Table 4 Showing Severity of COVID-19 Manifestations in COVID Group

\begin{tabular}{|l|l|}
\hline Severity & Number of Patients \\
\hline Mild & $30(30 \%)$ \\
Moderate & $25(25 \%)$ \\
Sever & $45(45 \%)$ \\
\hline
\end{tabular}

Table 5 Showing the Ocular Manifestations in Both Groups

\begin{tabular}{|l|l|l|l|}
\hline $\begin{array}{l}\text { Ocular } \\
\text { Disorder }\end{array}$ & $\begin{array}{l}\text { COVID Group } \\
\mathbf{n} \text { (\%) }\end{array}$ & $\begin{array}{l}\text { Control Group } \\
\mathbf{n} \text { (\%) }\end{array}$ & P value \\
\hline $\begin{array}{l}\text { Retinal vascular } \\
\text { occlusion }\end{array}$ & $5(5 \%)$ & $2(2 \%)$ & 0.006 \\
AION** & $2(2 \%)$ & $0(0 \%)$ & \\
Uveitis & $3(3 \%)$ & $0(0 \%)$ & \\
CSCR*** & $2(2 \%)$ & $0(0 \%)$ & \\
\hline
\end{tabular}

Notes: *number; $* * *$ anterior ischemic optic neuropathy; $* * *$ central serous chorioretinopathy.

were examined by a neurologist to exclude or confirm diagnosis.

The 3 cases of uveitis were attributed to autoimmune disorders after excluding the infectious causes.

\section{Discussion}

Before COVID-19, the incidence of ocular morbidities was as follows: vein occlusion, 1.02 per 1000 patientyears; artery occlusion, 1.3 per 100,000; uveitis (121 cases per 100,000; anterior ischemic optic neuropathy, 10.3 per 100,000; and central serous chorioretinopathy, 10 per $100,000 .^{23-27}$

In this study; those affected with COVID-19 showed ocular morbidities more than control group which did not suffer from COVID-19 infections and more than the incidence in population before the emergence of COVID-19 infection which support the relationship between the infection and the ocular comorbidities.

The difference between two groups regarding all other comparative values was insignificant except for the D-dimer and ESR in COVID group; which suggests inflammation. These comorbidities could be attributed to previous COVID-19 infections as we analyzed the other risk factors which showed insignificant difference between both groups. These risk factors include: clinical past history, basic metabolic panel, complete blood count, glycated hemoglobin, antinuclear antibody test, homocysteine levels, antithrombin III, coagulant protein $\mathrm{C}$, functional protein $\mathrm{S}$, resistance to activated $\mathrm{C}$ protein (factor $\mathrm{V}$ Leiden mutation), prothrombin gene mutation G20210A, anticardiolipin antibodies, prothrombin time, and international normalized ratio along with activated partial thromboplastin time.

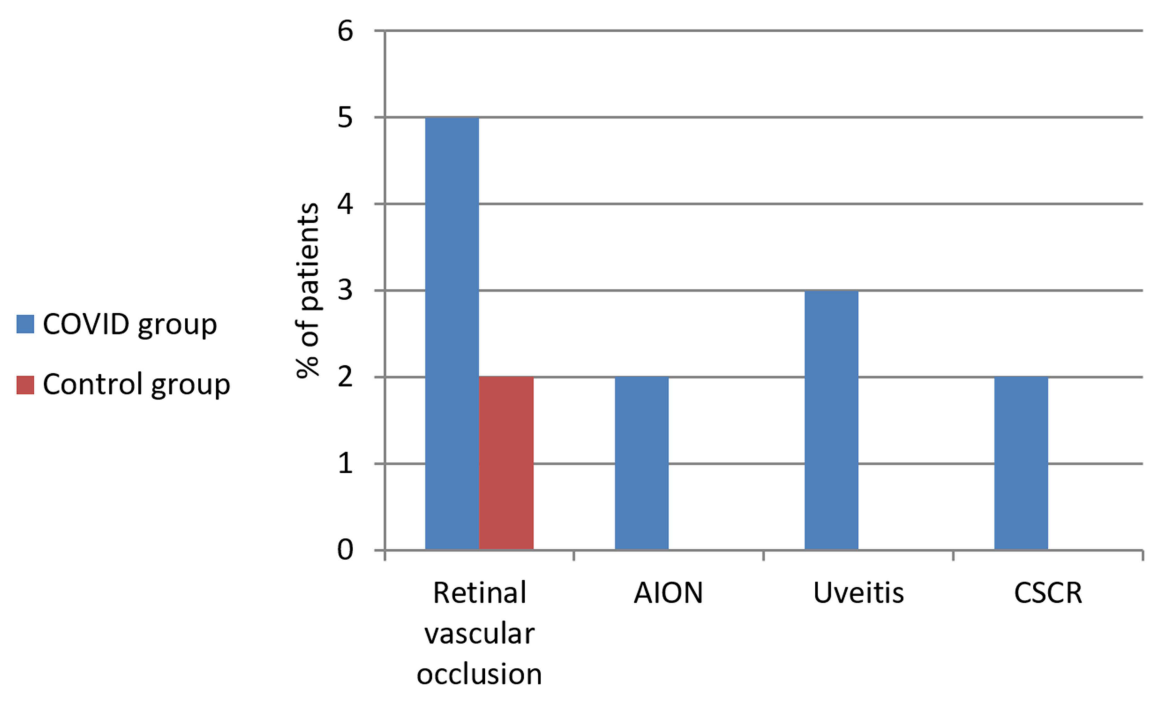

Figure 3 Ocular manifestations in both groups. 

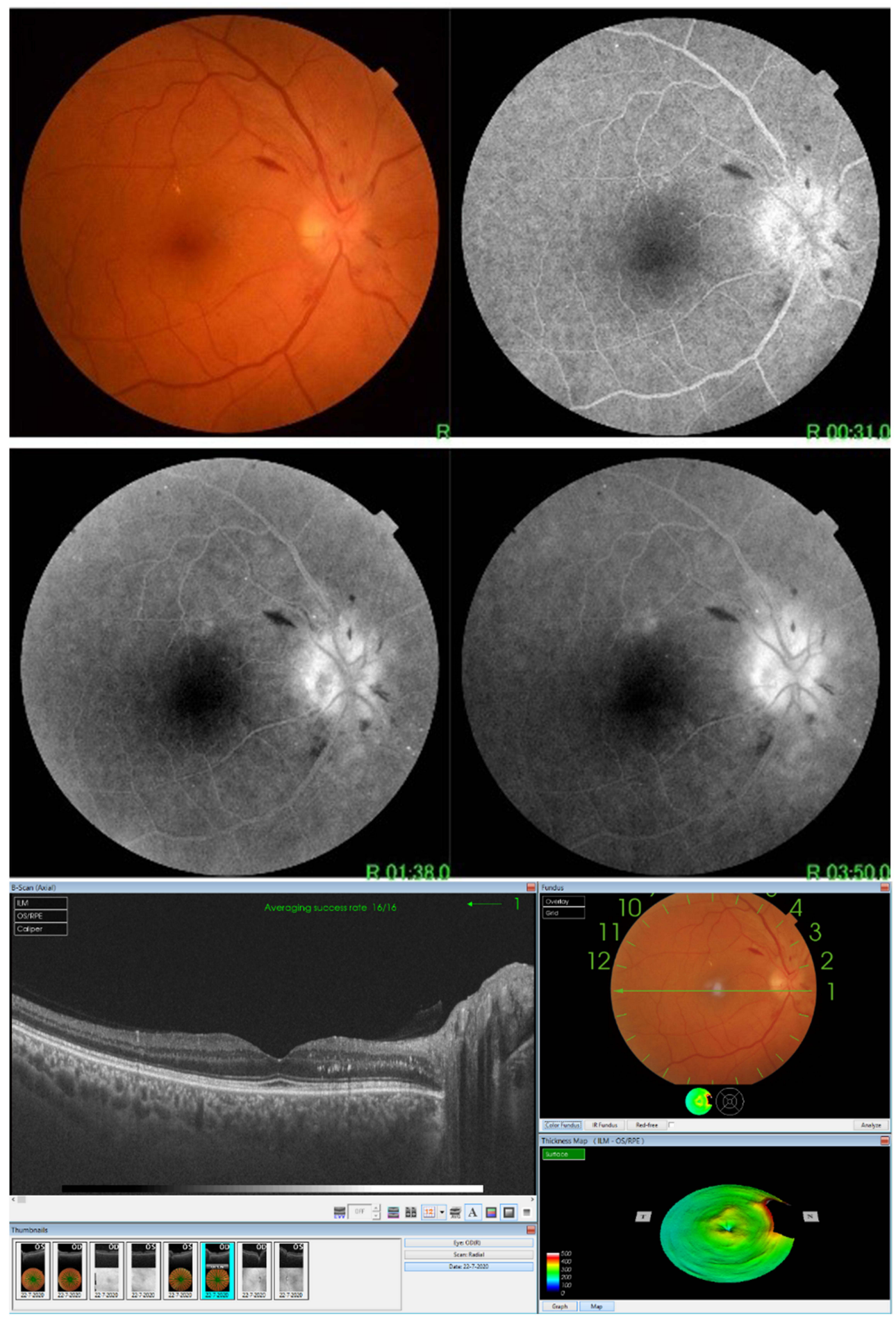

Figure $4 \mathrm{~A}$ case of AION (image on the upper part shows blurred disc margins in colour photo with hyperfluorescence leakage in early and late stages of F/A and image on the lower part shows OCT of the same case with edematous disc).

The comorbidities could be attributed to the elevated coagulation probability after the infection as the D-dimer is significantly high. Another explanation is the resultant endothelialitis ${ }^{28}$ which is caused by the
COVID-19 infection leading to a disturbance in capillary functions. The disturbance in capillary function could cause coagulation and decreased blood flow and ischemia. The other risk factors for the 

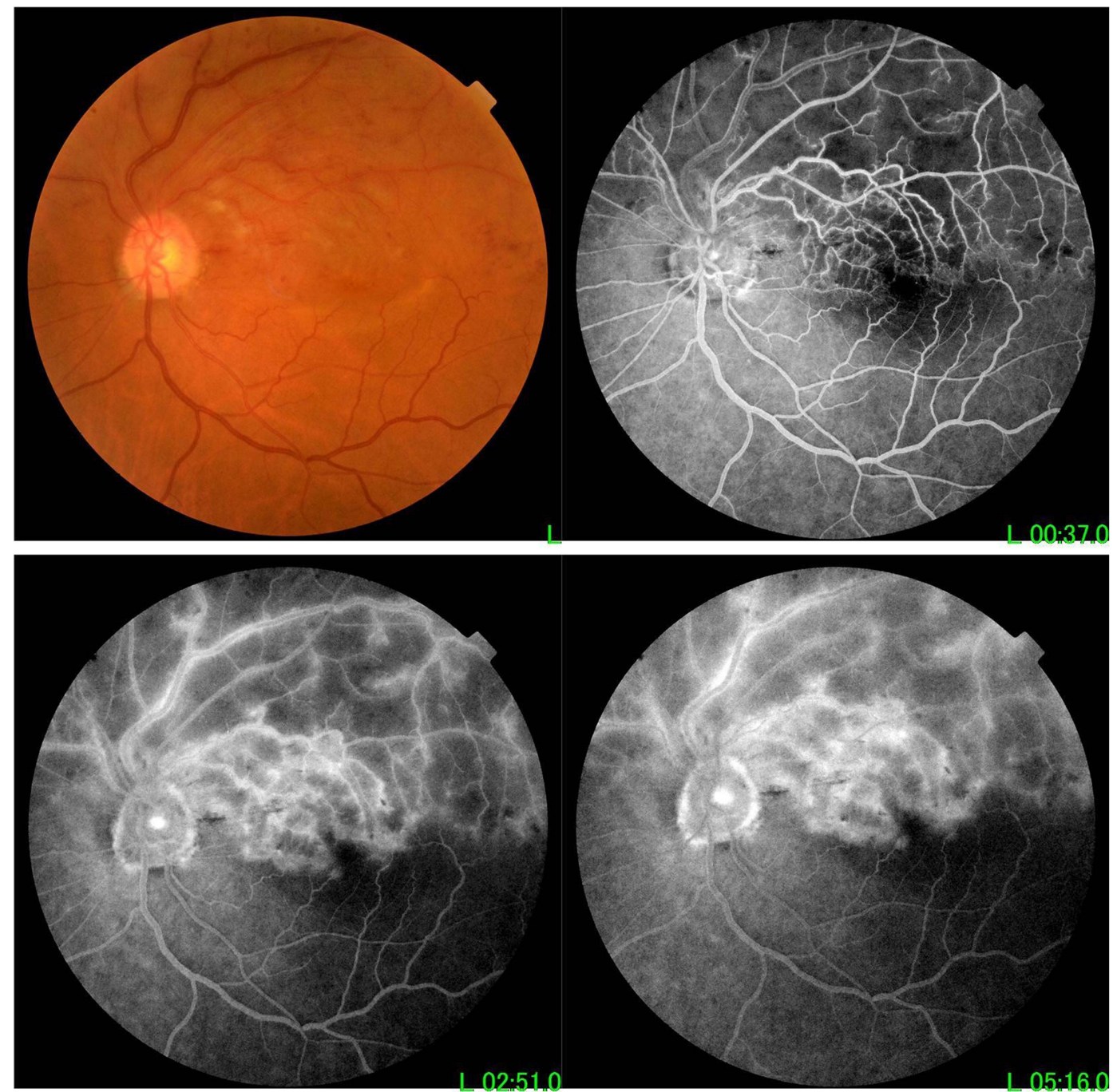

Figure 5 A case of BRVO (sectorial hemorrhages and exudates in superotemporal quadrant with dilated tortuous superotemporal retinal vein in colour photo with cystoid macular edema in early and late F/A photo).

ocular diseases occurred after recovery from COVID-19 infection were excluded by examination and investigations. Some reports suggested the occurrence of ocular problems after a COVID-19 infection, especially vascular problems, and explained the elevated possibility of coagulation induced by the infection. $^{29}$

The resultants ocular diseases were with higher incidence than in the normal population which focuses the cause on the COVID-19 infection. ${ }^{30,31}$

Some reports suggested the occurrence of endogenous endophthalmitis postcovid. ${ }^{32}$ Some reported ocular surface abnormalities after a COVID-19 infection, such as the occurrence of dryness and alternation in the osmolarity of the tears. ${ }^{33}$ Some other studies found that there is a correlation between the tear film distribution and the heart rate, which is affected by respiration and could be of importance in such study. ${ }^{34}$

The cause of uveitis could be infectious or autoimmune. In this study the cause is most likely to be autoimmune after exclusion of infectious causes in the 3 cases, suggesting immune alternation after COVID-19 infection. ${ }^{35}$

\section{Conclusion}

The COVID-19 infection could cause post-acute COVID19 infection or long COVID ocular morbidities which 

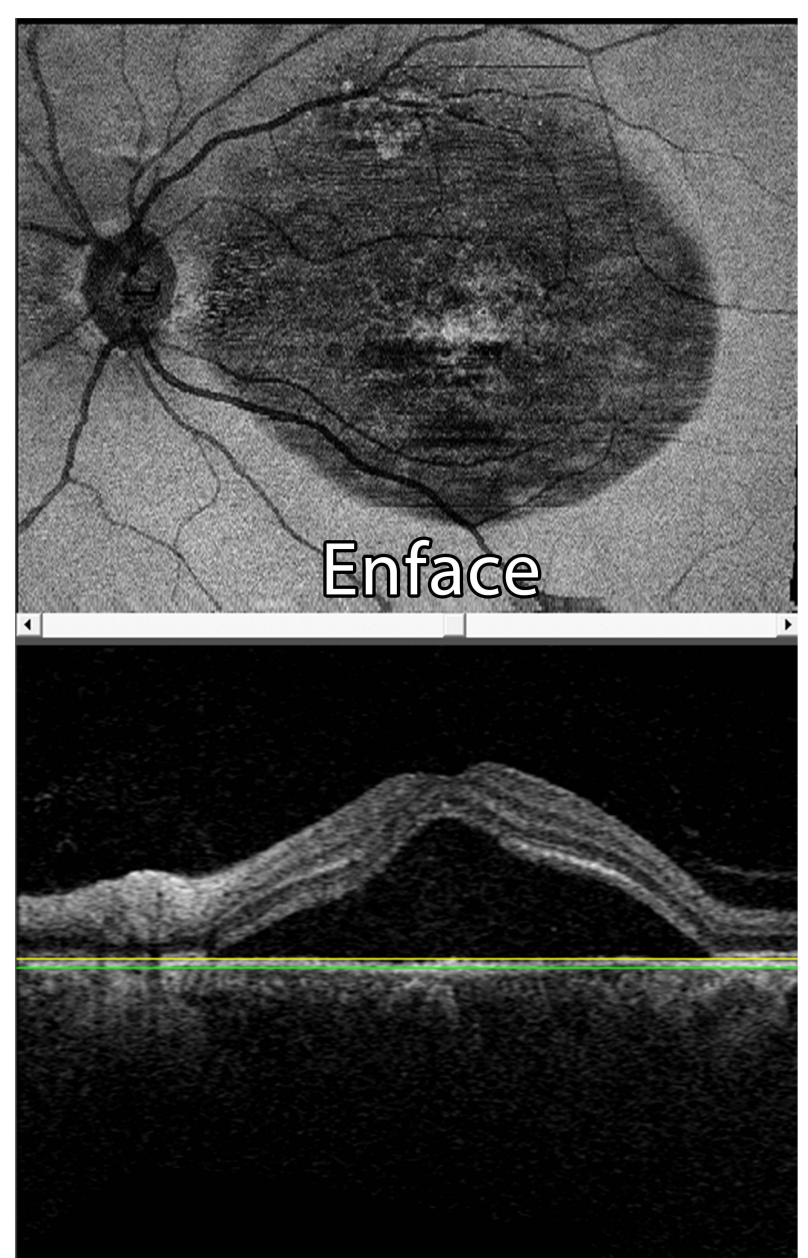

Figure 6 A case of CSCR (OCT shows sub-retinal fluid collection).

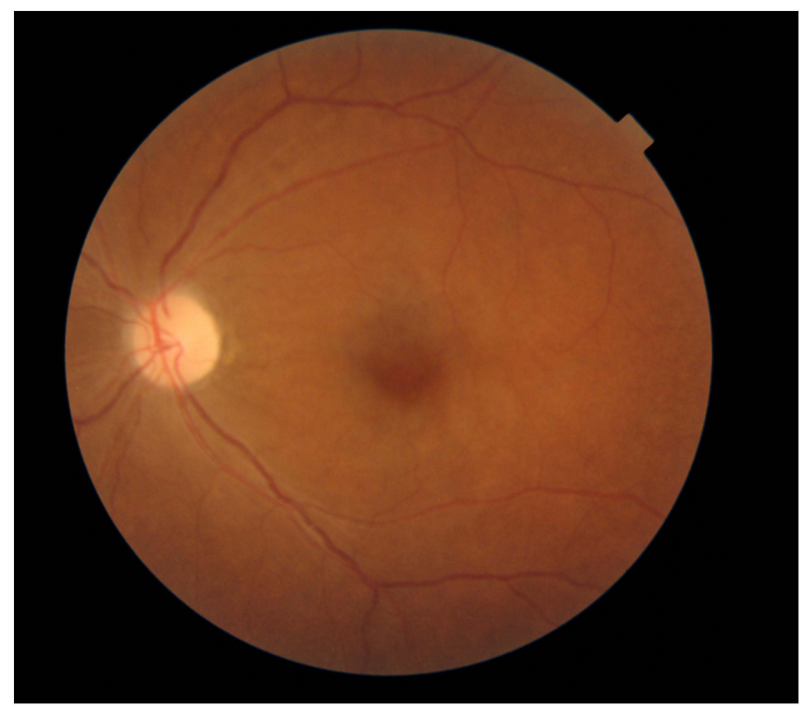

Figure 7 A case of CRAO (colour photo with cherry red spot). necessitate the ocular meticulous follow-up of COVID-19 patients after recovery.

\section{Limitations and Recommendations}

There was a small sample and lack of meticulous follow up, so more longitudinal studies are needed with larger numbers and in many countries.

\section{Data Sharing Statement}

Data related to this research are available upon request from corresponding author.

\section{Ethical Consideration}

This study was approved by Sohag University ethical committee IBR: Soh-Med-21-05-24

Written informed consent was taken from every participant.

\section{Acknowledgments}

We appreciate the efforts of Professor Hatem Ammar, the head of ophthalmology department, Sohag University for his support.

We would like to thank Dr Heba Khallaf for her effort in revising the manuscript.

\section{Author Contributions}

All authors made substantial contributions to conception and design, acquisition of data, or analysis and interpretation of data; took part in drafting the article or revising it critically for important intellectual content; agreed to submit to the current journal; gave final approval of the version to be published; and agree to be accountable for all aspects of the work.

\section{Disclosure}

All authors reported no conflicts of interest for this work.

This is to certify that: the article has not been presented in a meeting; the authors did not receive any financial support from any public or private sources; The authors have no financial or proprietary interest in the product, method, or material described herein.

\section{References}

1. Sohrabi C, Alsafi Z, O'Neill N, et al. World Health Organization declares global emergency: a review of the 2019 novel coronavirus (COVID-19). Int J Surg. 2020;76:71-76. doi:10.1016/j.ijsu.2020.02.034 
2. Rousseau A, Fenolland JR, Labetoulle M. SARS-CoV-2, COVID-19 et œil: le point sur les données publiées [SARS-CoV-2, COVID-19 and the eye: an update on published data]. J Fr Ophtalmol. 2020;43 (7):642-652. doi:10.1016/j.jfo.2020.05.003

3. Wu P, Duan F, Luo C, et al. Characteristics of ocular findings of patients with coronavirus disease 2019 (COVID-19) in Hubei Province, China. JAMA Ophthalmol. 2020;138(5):575-578. doi:10.1001/jamaophthalmol.2020.1291

4. Napoli PE, Nioi M, Fossarello M. The "Quarantine Dry Eye": the lockdown for coronavirus disease 2019 and its implications for ocular surface health. Risk Manag Healthc Policy. 2021;14:1629-1636. doi:10.2147/RMHP.S277067

5. Napoli PE, Mangoni L, Gentile P, et al. A panel of broad-spectrum antivirals in topical ophthalmic medications from the drug repurposing approach during and after the coronavirus disease 2019 era. J Clin Med. 2020;9(8):2441. doi:10.3390/jcm9082441

6. Barton LM, Duval EJ, Stroberg E, et al. COVID-19 Autopsies, Oklahoma, USA. Am J Clin Pathol. 2020;153(6):725-733. doi:10.1093/ajcp/aqaa062

7. Bertoli F, Veritti D, Danese C, et al. Ocular findings in COVID-19 patients: a review of direct manifestations and indirect effects on the eye. $J$ Ophthalmol. 2020;2020:4827304. doi:10.1155/2020/ 4827304

8. Xia J, Tong J, Liu M, et al. Evaluation of coronavirus in tears and conjunctival secretions of patients with SARS-CoV-2 infection. J Med Virol. 2020;92(6):589-594. doi:10.1002/jmv.25725

9. Mahmoud H, Ammar H, El Rashidy A, et al. Assessment of coronavirus in the conjunctival tears and secretions in patients with SARS-CoV-2 infection in Sohag Province, Egypt. Clin Ophthalmol. 2020;14:2701-2708. doi:10.2147/OPTH.S270006

10. Qing H, Li Z, Yang Z, et al. The possibility of COVID-19 transmission from eye to nose. Acta Ophthalmol. 2020;98(3):e388. PMID 32189463. doi: 10.1111/aos.14412

11. Hoenig LJ. The eye and COVID-19 pandemic. Clin Dermatol. 2020;38(4):506. doi:10.1016/j.clindermatol.2020.03.013.

12. Dockery DM, Rowe SG, Murphy MA, et al. The ocular manifestations and transmission of COVID-19: recommendations for prevention. $J$ Emerg Med. 2020;59(1):137-140. doi:10.1016/j. jemermed.2020.04.060

13. Mahmoud H, Hamody A, Hefny M, et al. Evaluation of anti-SARSCoV-2 IgA in the conjunctival secretions of COVID-19 patients. Clin Ophthalmol. 2021;15:1933-1937. doi:10.2147/OPTH.S312942

14. Napoli PE, Nioi M, d'Aloja E, et al. The ocular surface and the coronavirus disease 2019: does a dual 'ocular route' exist? J Clin Med. 2020;9(5):1269. doi:10.3390/jcm9051269

15. Napoli PE, Nioi M, d'Aloja E, et al. Safety recommendations and medical liability in ocular surgery during the COVID-19 pandemic: an unsolved dilemma. J Clin Med. 2020;9(5):1403. doi:10.3390/ jcm9051403

16. Pei X, Jiao X, Lu D, et al. How to face COVID-19 in ophthalmology practice. Med Hypothesis Discov Innov Ophthalmol. 2020;9 (3):164-171. doi:10.51329/mehdiophthal1406

17. Chippa V, Aleem A, Anjum F. Post acute coronavirus (COVID-19) syndrome. In: StatPearls. Treasure Island (FL): StatPearls Publishing; 2021.

18. Maltezou HC, Pavli A, Tsakris A. Post-COVID syndrome: an insight on its pathogenesis. Vaccines (Basel). 2021;9(5):497. PMID: 34066007; PMCID: PMC8151752. doi:10.3390/vaccines9050497
19. Madrid-Mejía W, Gochicoa-Rangel L, Padilla JRP, et al. Improvement in walking distance lags raise in lung function in post-COVID patients. Arch Bronconeumol. 2021. PMID: 34054195; PMCID: PMC8150358. doi:10.1016/j.arbres.2021.04.027

20. Medvedev VE, Frolova VI, Gushanskaya EV, et al. [Astenic disorders within the framework of post-covid syndrome]. Zh Nevrol Psikhiatr Im $S$ S Korsakova. 2021;121(4):152-158. PMID: 34037369. [Russian]. doi:10.17116/jnevro2021121041152

21. Iqbal FM, Lam K, Sounderajah V, et al. Characteristics and predictors of acute and chronic post-COVID syndrome: a systematic review and meta-analysis. EClinicalMedicine. 2021;36:100899. PMID: 34036253; PMCID: PMC8141371. doi:10.1016/j.eclinm.2021.100899

22. Augustin M, Schommers P, Stecher M, et al. Post-COVID syndrome in non-hospitalised patients with COVID-19: a longitudinal prospective cohort study. Lancet Reg Health Eur. 2021;6:100122. PMID: 34027514; PMCID: PMC8129613. doi:10.1016/j.lanepe.2021.100122

23. Lee J, Choe HR, Park SH, et al. Impact of kidney transplantation on the risk of retinal vein occlusion in end-stage renal disease. Sci Rep. 2021;11(1):11583. doi:10.1038/s41598-021-90765-8

24. Leavitt JA, Larson TA, Hodge DO, Gullerud RE. The incidence of central retinal artery occlusion in Olmsted County, Minnesota. Am J Ophthalmol. 2011;152(5):820-3.e2. doi:10.1016/j.ajo.2011.05.005

25. González MM, Solano MM, Porco TC, et al. Epidemiology of uveitis in a US population-based study. J Ophthalmic Inflamm Infect. 2018;8 (1):6. doi:10.1186/s12348-018-0148-5

26. Hattenhauer MG, Leavitt JA, Hodge DO, et al. Incidence of nonarteritic anterior ischemic optic neuropathy. Am J Ophthalmol. 1997;123(1):103-107. doi:10.1016/s0002-9394(14)70999-7

27. Liew G, Quin G, Gillies M, et al. Central serous chorioretinopathy: a review of epidemiology and pathophysiology. Clin Exp Ophthalmol. 2013;41(2):201-214. doi:10.1111/j.1442-9071.2012.02848.x

28. Bugra A, Das T, Arslan MN, et al. Postmortem pathological changes in extrapulmonary organs in SARS-CoV-2 rt-PCR-positive cases: a single-center experience. Ir J Med Sci. 2021:1-11. Epub ahead of print. doi:10.1007/s11845-021-02638-8.

29. Savastano A, Crincoli E, Savastano MC, et al. Peripapillary retinal vascular involvement in early post-COVID-19 patients. J Clin Med. 2020;9(9):2895. doi:10.3390/jcm9092895

30. Li Y, Hall NE, Pershing S, et al. Age, gender, and laterality of retinal vascular occlusion: a retrospective study from the IRIS ${ }^{\circledR}$ Registry. Ophthalmol Retina. 2021. PMID: 33991710. doi:10.1016/j. oret.2021.05.004

31. Hayreh SS. Ischemic optic neuropathy. Prog Retin Eye Res. 2009;28 (1):34-62. PMID: 19063989. doi:10.1016/j.preteyeres.2008.11.002

32. Shah KK, Venkatramani D, Majumder PD. A case series of presumed fungal endogenous endophthalmitis in post COVID-19 patients. Indian J Ophthalmol. 2021;69(5):1322-1325. PMID: 33913891. doi:10.4103/ijo.IJO_3755_20

33. Gambini G, Savastano MC, Savastano A, et al. Ocular surface impairment after coronavirus disease 2019: a cohort study. Cornea. 2021;40 (4):477-483.PMID: 33214412. doi:10.1097/ICO.0000000000002643

34. Napoli PE, Nioi M, d'Aloja E, et al. The bull's eye pattern of the tear film in humans during visual fixation on en-face optical coherence tomography. Sci Rep. 2019;9(1):1413. doi:10.1038/s41598-018-38260-5

35. Braceros KK, Asahi MG, Gallemore RP. Visual snow-like symptoms and posterior uveitis following COVID-19 infection. Case Rep Ophthalmol Med. 2021;2021:6668552. doi:10.1155/2021/6668552 


\section{Publish your work in this journal}

The Journal of Multidisciplinary Healthcare is an international, peerreviewed open-access journal that aims to represent and publish research in healthcare areas delivered by practitioners of different disciplines. This includes studies and reviews conducted by multidisciplinary teams as well as research which evaluates the results or conduct of such teams or healthcare processes in general. The journal covers a very wide range of areas and welcomes submissions from practitioners at all levels, from all over the world. The manuscript management system is completely online and includes a very quick and fair peer-review system. Visit http://www.dovepress.com/testimonials. php to read real quotes from published authors. 